\title{
Thoracoscopic sympathectomy: techniques and outcomes
}

\section{J. Patrick Johnson, M.D., Samuel S. Ahn, M.D., William C. Choi, M.D., Jeffery E. Masciopinto,} M.D., Kee D. Kim, M.D., Aaron G. Filler, M.D., and Antonio A. F. DeSalles, M.D.

Divisions of Neurosurgery and Vascular Surgery, Department of Surgery, School of Medicine, University of California, Los Angeles, Los Angeles, California; and Department of Neurological Surgery, Montreal Neurological Institute, Montreal, Quebec, Canada

Thoracic sympathectomy is an important option in the treatment of palmar hyperhidrosis and pain disorders. Earlier surgical procedures were highly invasive with known morbidity, acceptable outcome, and established recurrence rates that were the limitations to considering surgical treatment.

Thoracoscopic sympathectomy is a minimally invasive procedure that allows detailed visualization of the sympathetic ganglia and minimal postoperative morbidity; however, outcome studies of this technique have been limited. The authors treated 39 patients with 60 thoracoscopic procedures, and the outcomes in this small series were equivalent to previously established open surgical techniques; however, operative moribidity rates, hospital stay, and time of return to normal activity were substantially reduced. Complications and recurrence of symptoms were also comparable to previous reports. Overall patient satisfaction and willingness to repeat the operative procedure ranged from 66 to $96 \%$ in all patients. Patients and physicians can consider minimally invasive thoracoscopic sympathectomy procedures as an option to treat sympathetically mediated disorders because of the procedure's reduced morbidity and at least equivalent outcome rates in comparison to other treatments.

Key Words * thoracoscopic sympathectomy * sympathetic ganglia * endoscopy

Thoracoscopic sympathectomy is performed using minimally invasive endoscopic techniques first described by Kux[17] in 1951 for the treatment of hyperhidrosis. There was little interest until the past decade[4,9,12,15,22-26,28] when video-assisted endoscopic imaging made minimally invasive procedures technically feasible. Treatment of sympathetically mediated syndromes affecting the upper extremities including hyperhidrosis, pain syndromes (causalgia or reflex sympathetic dystrophy now commonly referred to as complex regional pain syndrome), and Raynaud's syndrome are the primary indications for thoracoscopic sympathectomy.[1,4,9,12,13,21,24] Thoracoscopy provides a magnified view of the sympathetic chain and adjacent anatomy for precise surgical resection of the sympathetic ganglia that may potentially reduce morbidity associated with open thoracotomy and/or supraclavicular or posterior paraspinal procedures.[12,22] Shorter hospital stays and reduced morbidity rates, resulting in increased patient demand for this procedure and improved satisfaction that reduce costs, now make thoracoscopic sympathectomy the preferred procedure for these disorders; however, long-term outcome studies have been limited. 


\section{CLINICAL MATERIAL AND METHODS}

\section{Patients and Diagnosis}

Thirty-nine patients underwent 60 thoracoscopic sympathectomy procedures between 1993 and 1997 for sympathetically mediated disorders. These procedures were performed for unilateral or bilateral symptoms: 18 patients underwent a unilateral thoracoscopic sympathectomy procedure, whereas 11 patients with bilateral symptoms underwent staged thoracoscopic procedures several weeks apart in the early part of this series (1993-1995). During the past 2 years, 10 patients with bilateral symptoms underwent sequentially staged thoracoscopic procedures on the same day.

\section{Indications and General Considerations}

Patients with sympathetically mediated syndromes need initial medical treatment prior to surgical consideration. Other conservative treatment regimens had failed in all patients who underwent sympathectomy procedures. Imaging with chest radiography and computerized tomography scanning or magnetic resonance imaging of the cervical and thoracic spine and brachial plexus should be considered in each individual case. Psychological evaluation is an important component to be considered in the evaluation of chronic pain patients. Stellate ganglion anesthetic blocks were used for diagnostic confirmation that symptoms were responsive to sympathetic blockade.

\section{SURGICAL PROCEDURES AND INSTRUMENTS}

\section{Intubation and Positioning}

General anesthesia was administered, and patients underwent selective intubation with single-lung ventilation required for thoracoscopic sympathectomy procedures. Patient positioning evolved during the present series (Table 1).

\begin{tabular}{|ccc|}
\hline \multicolumn{3}{c|}{ TABLE 1 } \\
SYMPATHECTOMN PROCEDURES IN WHKH UN LATER, L \\
COMPARED WITH BILATERAL APPROACHES WERE USED \\
IN 39 PATIENTS \\
\hline \hline Approach & No. of Patierts & No. of Proc edur es \\
\hline unilat & 18 & 18 \\
tilat (staged) & 11 & 22 \\
tilat (same day) & 10 & 20 \\
\hline
\end{tabular}

Early in the series, patients underwent surgery in a lateral position with side requiring surgery up (Fig. 1), and patients with bilateral symptoms underwent surgery on the opposite side several weeks later. Later in the series, those patients with bilateral symptoms underwent bilateral sympathectomies with repositioning for an immediate second-stage procedure on the opposite side. Currently, patients requiring bilateral sympathectomies have the procedure performed in a supine position with exposure of both axillary regions in immediately staged procedures. 


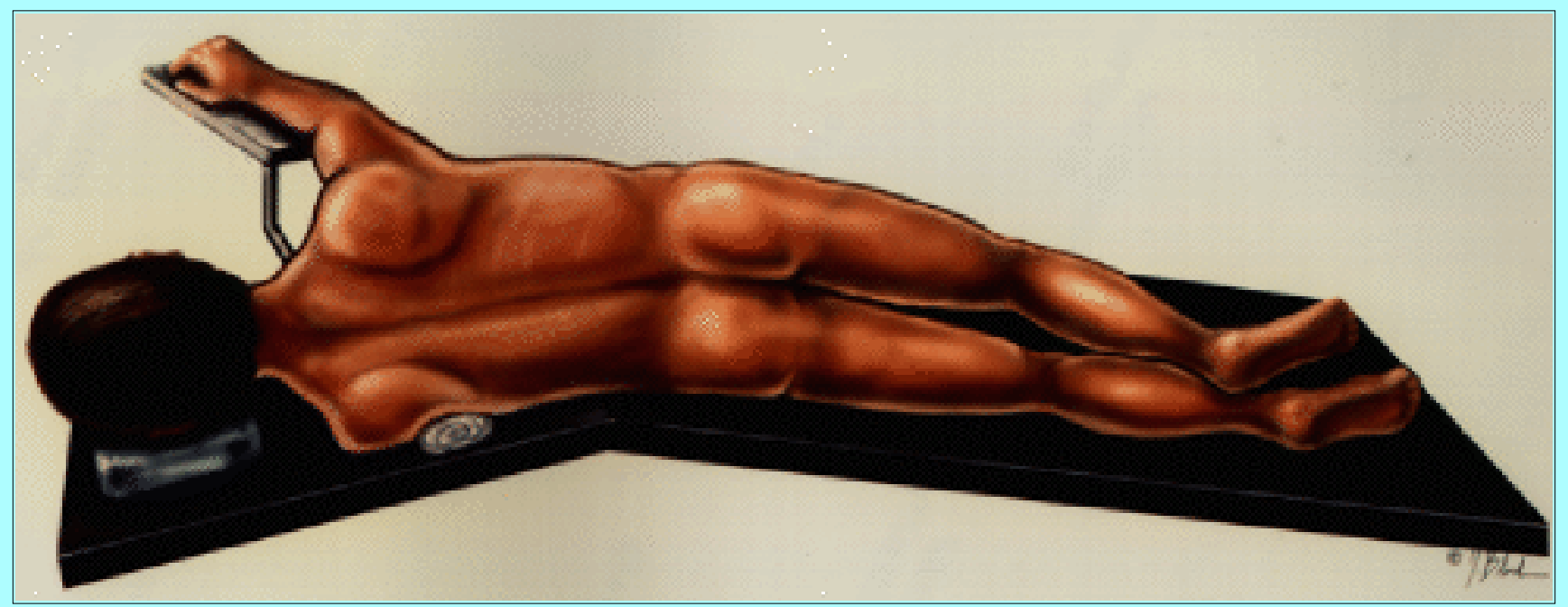

Fig. 1. Artist's drawing depicting the lateral positioning of the patient (same as for a thoracotomy) for right thoracoscopic sympathectomy.

\section{Equipment and Instruments}

The equipment and instruments needed for the thoracoscopic sympathectomy procedure are available in most operating rooms. A 5- to 10-mm diameter rigid endoscope (with 0,30 , and 60š angled lenses) with a camera and video monitor are required for visualiztion; endoscopic instrumentation includes a 5-mm diameter miniMetzenbaum-type scissors with monopolar electrocautery, a 10-mm diameter curved hemostat grasper, and a 5-mm diameter suction/irrigator. Optional instruments are a 10-mm right-angled clamp, a 10-mm laparoscopic clip applier, and a laparoscopic retractable fan-type retractor.

\section{Ports and Port Placement}

Three ports are recommended but occasionally only two ports are needed. Port placement and location are important for good endoscopic visualization and manipulation of the instruments during the procedure. The endoscope is placed in one port, and the instruments are placed in the remaining ports (Fig. 2). Port insertion is similar to chest tube placement through a 2-cm skin incision into the intercostal space, avoiding the neurovascular bundle. A 15-mm Flexi-path port (Ethicon Inc., Cincinnati, OH) is inserted with a blunt introducer. The ipsilateral lung is deflated, and the endoscope is placed through the first port to assist placement of the subsequent instrument ports. The endoscope is placed through a port in the third or fourth intercostal space in the midaxillary line, and the instrument ports are both placed in the anterior and posterior axillary line of the fifth or sixth intercostal space. However, the endoscope and instruments can be interchanged among any of the ports depending on the surgeon's preference. Additional ports can be placed for lung retraction or to assist the procedure as needed. 


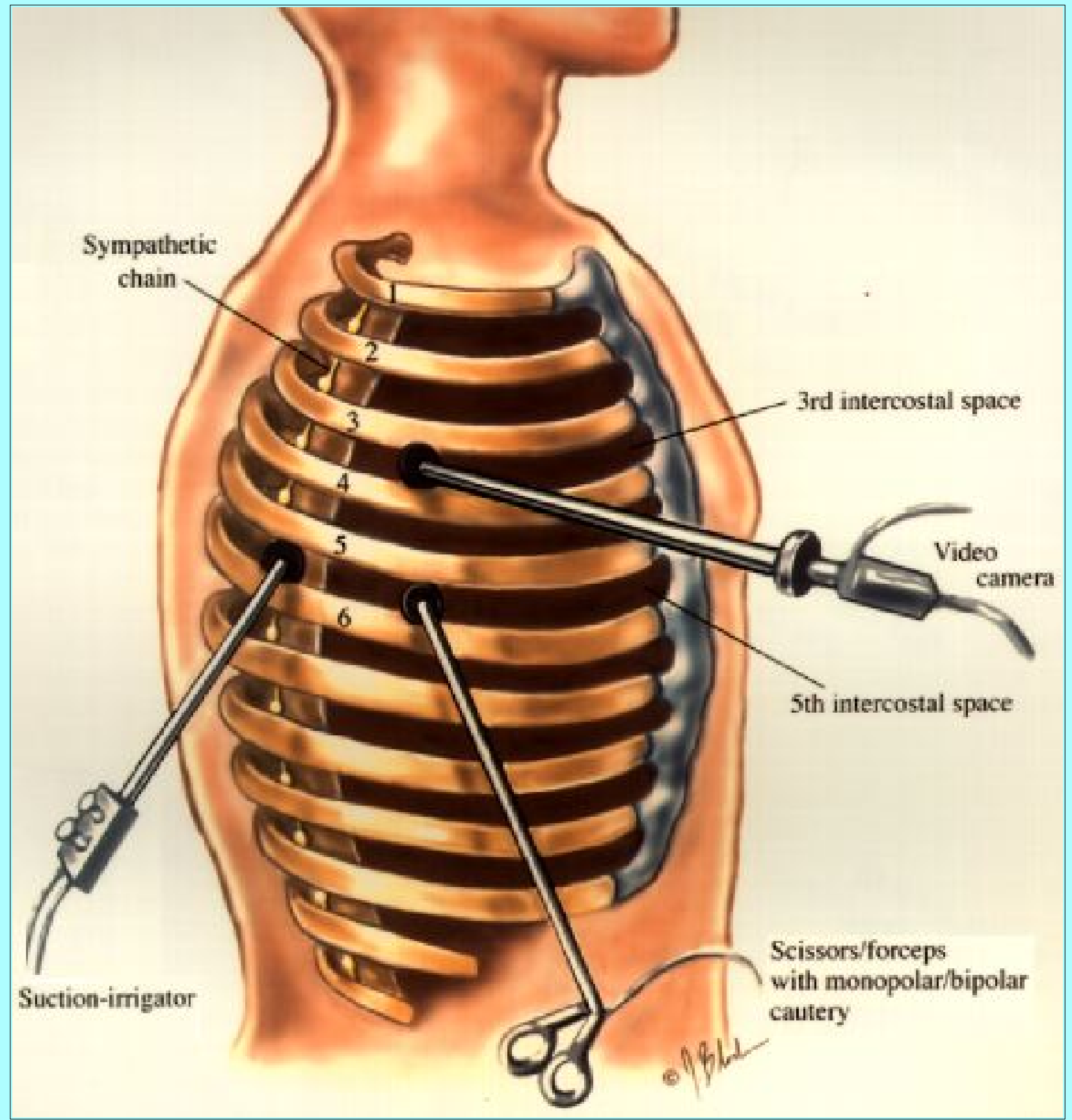

Fig. 2. Artist's drawing depicting the endoscopic port locations and instrument placement.

\section{Steps of the Procedure}

The thoracoscopic procedure begins with exploration of the thoracic cavity, and any adhesions of the lung and the parietal pleura are coagulated and divided. The lung is then retracted with a fan retractor and is assisted by rotating the operating table and positioning the patient in a reverse Trendelenburg position, allowing the lung to fall away from the upper thoracic vertebral column.

Important anatomical landmarks begin with identification of ribs 1 through 4 , and the sympathetic chain is visualized beneath the pleura coursing over each rib head (Fig. 3). The pleura over the sympathetic chain should not be "palpated" with endoscopic instruments because this causes hyperemia and obscures visualization. The extent of sympathetic chain removed can be tailored to the individual patient. Sympathetic resection of the T-2 ganglion is the minimum procedure, and a more complete sympathetic denervation of the upper extremity and axilla involves excision from immediately below the stellate 
ganglion to T-4. The stellate ganglion is located within the fat pad enveloping the subclavian artery. The intercostal vessels course over the mid-portion of the vertebral body, and the azygos veins draining the intercostal veins should be avoided during dissection of the sympathetic chain.

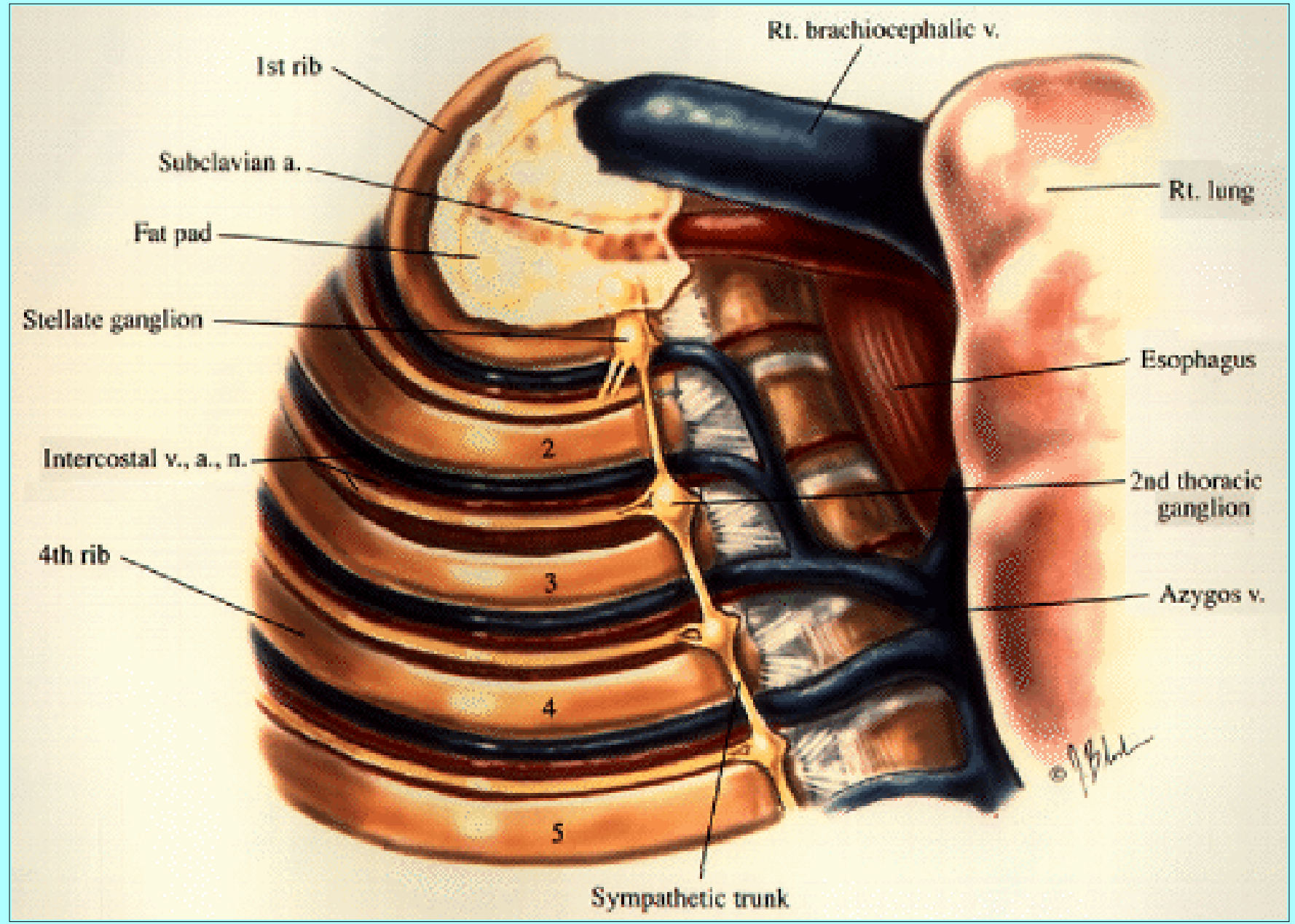

Fig. 3. Artist's drawing depicting the intrathoracic anatomy of right upper thorax demonstrating location of sympathetic ganglia and chain. a. = artery; n. = nerve; v. = vein .

The dissection begins by incising the pleura over the sympathetic chain with curved scissors to gain exposure cephalad to the stellate ganglion (Fig. 4). The sympathetic chain is then dissected with scissors from its bed by dividing the rami communicantes at each level (Fig. 5 left). A dissection plane immediately beneath the sympathetic chain avoids the underlying intercostal vessels, but occasionally intercostal vessels course over the sympathetic chain and require either cauterization or clipping and dividing. 


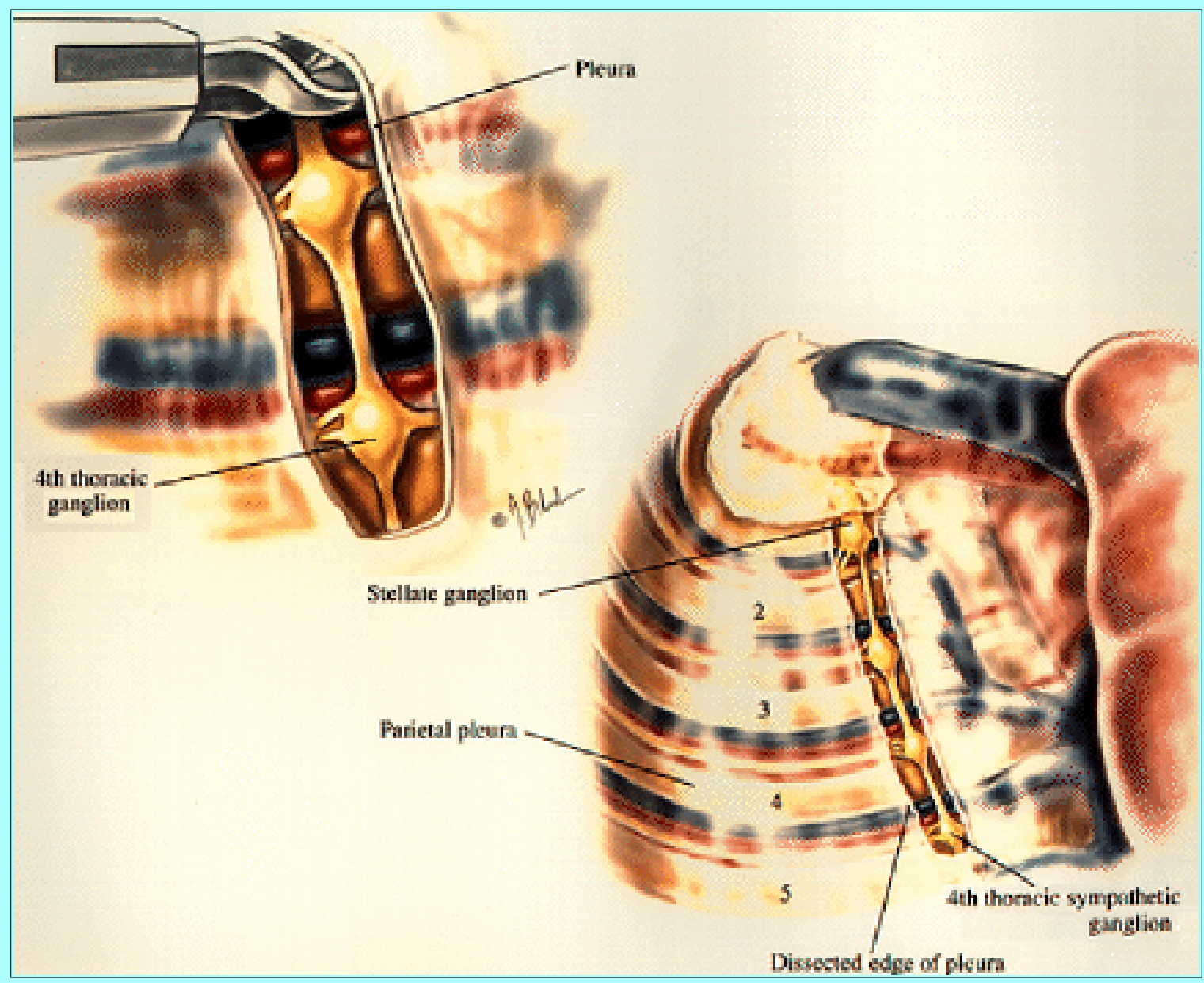

Fig. 4. Artist's drawings illustrating (left) dissection of pleura overlying the sympathetic chain at T-4 and (right) completed dissection of pleura overlying the sympathetic chain from T1-4.

Resection of the sympathetic chain is extended cephalad to the inferior aspect of the stellate ganglion to achieve adequate sympathetic denervation of the lower trunk of brachial plexus while avoiding injury to the stellate ganglion. The nerve of Kuntz, a large branch that extends caudally from the stellate ganglia, (Fig. 5 right) is also found within the fat pad. The stellate ganglion should remain undisturbed to avoid injury that can result in Horner's syndrome. The sympathetic chain is then excised and sent for histopathological evaluation. The dissection bed is irrigated and assured for hemostasis, and a 20 to 24 French chest tube is inserted through one of the ports and positioned endoscopically. The instrument ports are then removed sequentially, the lung is reinflated by the anesthesiologist, and the port incisions are closed in two layers. 


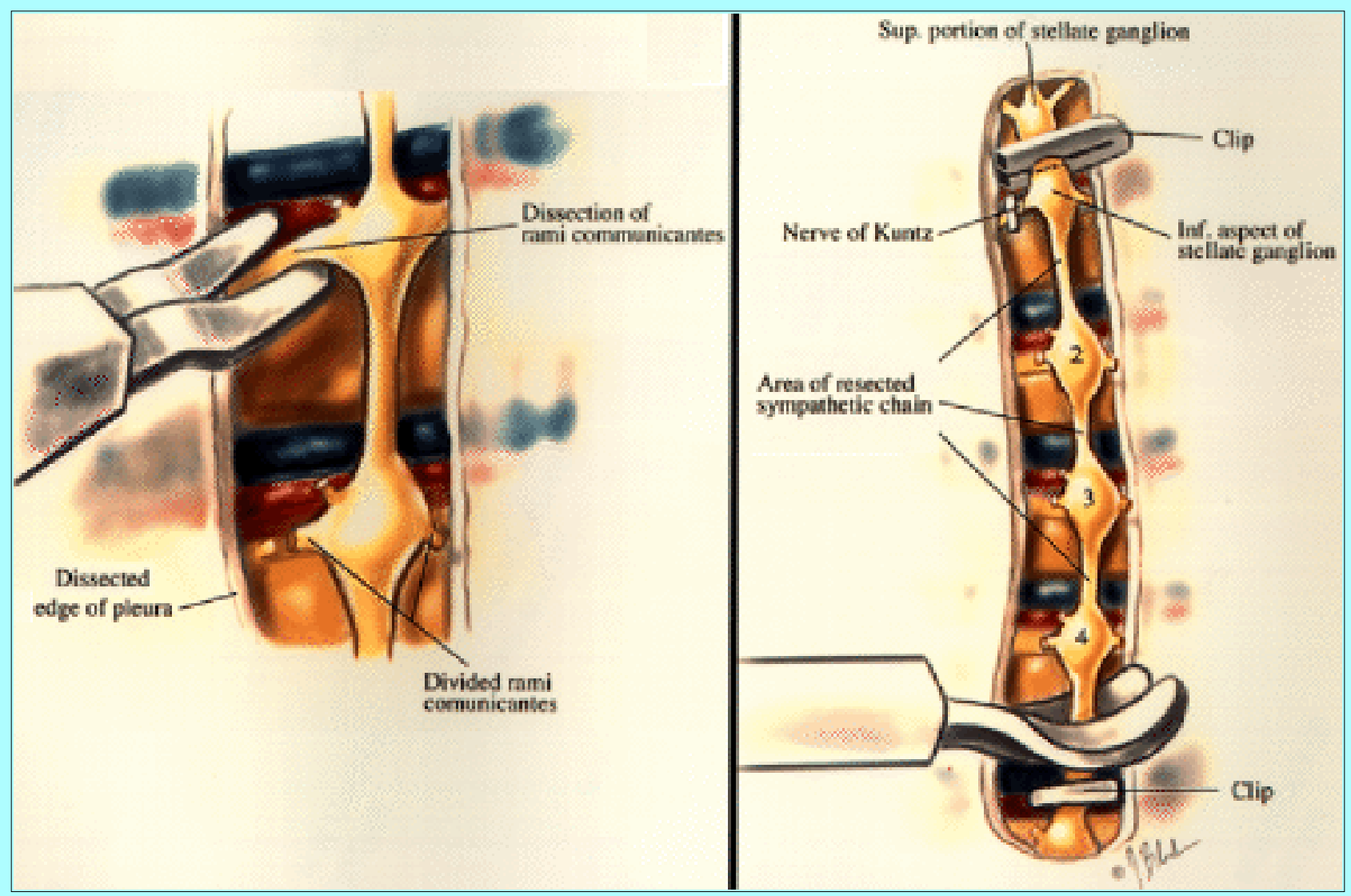

Fig. 5. Artist's drawings illustrating (left) division of rami communicantes at each level, and (right) division of the sympathetic chain at the inferior aspect of the stellate ganglion and T-4.

\section{Postoperative Care}

The chest tube is initially placed on negative $15-\mathrm{cm}$ water suction, and an immediate chest $\mathrm{x}$-ray film is obtained to verify the absence of pneumothorax. The chest tube is then placed on water seal and removed either the next day or possibly the same day. Oral analgesics are adequate for pain control, and the patient is discharged when ambulatory.

\section{Outcome Analysis}

In our patient group follow up was 6 months to 4 years, with annual clinical evaluations of all patients after thoracoscopic sympathectomy. Patient data were derived from clinical examinations and/or telephone interviews. Clinical outcome questionnaires were administered to patients, collected by staff other than the treating surgeon, and a retrospective analysis was performed.

Patients with hyperhidrosis were evaluated for the presence or absence of sweaty palms and surgical complications, and delayed complications of compensatory hyperhidrosis or gustatory sweating were also determined. Pain and vasculitis disorders in patients were evaluated with the Oswestry Pain Scale to determine outcomes and to quantify the severity of their symptoms before and after sympathectomy. The incidence and severity of recurrent symptoms were evaluated by the same methods. Patients were also evaluated for their "overall satisfaction" with the procedure and for current clinical symptoms. In the same manner, they were also queried regarding their "willingness to repeat" the procedure.

\section{RESULTS}


Patients with hyperhidrosis comprised the largest group undergoing thoracoscopic sympathectomy, and they also had the highest success rates (Tables 2 and 3). Although 29\% of these patients experienced delayed complications of compensatory hyperhidrosis (manifesting as sweating in the trunk/torso), most patients were sufficiently satisfied that they claimed they would undergo the procedure again (Tables 3 and 4).

\begin{tabular}{|cc|}
\hline \multicolumn{2}{|c|}{ TABLE 2 } \\
$\begin{array}{c}\text { DIAGNOSIS IN PATIENTS WHO UNDERWENT THORACOSCOPIC } \\
\text { SVMPATHEC TOM }\end{array}$ \\
\hline \hline Symptom* & No. of Patierts \\
\hline hyperhidrosis & 24 \\
causalgia/RSD DRPS & 10 \\
Raynaud's syndrome & 5 \\
\hline x CRPS = comple x regional pain syndrome; RSD = reflex \\
sym pathetic dystrophy.
\end{tabular}

\begin{tabular}{|c|c|c|c|c|}
\hline \multicolumn{5}{|c|}{$\begin{array}{c}\text { TABLE } 3 \\
\text { OUTCOME IN } 24 \text { PATIENTS WITH HY PERH DROSI* }\end{array}$} \\
\hline Symptom & $\begin{array}{c}\text { Relief of } \\
\text { Symptorns }\end{array}$ & $\begin{array}{l}\text { Partial Reli ef } \\
\text { of Symptoms }\end{array}$ & $\begin{array}{l}\text { Recurrert } \\
\text { Symptorns }\end{array}$ & $\begin{array}{l}\operatorname{Lost} t_{0} \\
\text { Follow } U_{p}\end{array}$ \\
\hline hyperhidrosis & 23 & 1 & 0 & 0 \\
\hline
\end{tabular}

\begin{tabular}{|c|c|c|}
\hline \multicolumn{3}{|c|}{$\begin{array}{c}\text { TABLE } 4 \\
\text { PATENT SAT SFACTION AND WILLINGNESS TO UNDERGO } \\
\text { RE PEATED PROCEDURE }\end{array}$} \\
\hline Symptom & $\begin{array}{l}\text { Patient Satis- } \\
\text { faction Rate }\end{array}$ & $\begin{array}{c}\text { Willingness } \\
\text { to R epeat }\end{array}$ \\
\hline $\begin{array}{l}\text { hyperhidrosis } \\
\text { RSD Nasculitis }\end{array}$ & $\begin{array}{l}96 \% \\
66 \%\end{array}$ & $\begin{array}{l}92 \% \\
75 \%\end{array}$ \\
\hline
\end{tabular}

The number of patients treated for pain syndromes or vasculitic disorders was smaller than for hyperhidrosis (Table 2). Their response to treatment was very high immediately following surgery; however these outcomes were diminished after more than 6 months postoperatively (Tables 5 and 6), and the recurrence of symptoms was variable among those patients. Their overall satisfaction and willingness to repeat the operative treatment was correspondingly decreased (Table 4).

\begin{tabular}{|lccc|}
\hline \multicolumn{5}{c|}{ TABLE 5 } \\
OUTCOMES IN 15 PATIENTS WITH PAIN AND YASCULITIS DISORDERS \\
\hline \hline \multicolumn{1}{|c|}{ Symptom } & $\begin{array}{c}\text { Relief of } \\
\text { Symptorns }\end{array}$ & $\begin{array}{c}\text { Recurrence } \\
\text { of Symptons }\end{array}$ & $\begin{array}{c}\text { Lost to } \\
\text { Follow Up }\end{array}$ \\
\hline $\begin{array}{l}\text { RSDitausalgia.CRPS } \\
\text { (10 patients) }\end{array}$ & 6 & 3 & 1 \\
$\begin{array}{l}\text { Raynaud's syndrome hasculitis } \\
\text { (5 patients) }\end{array}$ & 4 & 1 & 0 \\
\hline
\end{tabular}




\begin{tabular}{|ccc|}
\hline \multicolumn{3}{c|}{$\begin{array}{c}\text { TABLE } 6 \\
\text { OSWESTRY DISAELITV QUOTENT OUTCOMES FOR PAIN AND } \\
\text { YASCULITIS DISORDERS }\end{array}$} \\
\hline \hline Symptom & 1 mo Postop & $>6$ mos Post op \\
\hline RSDicausalgia/CRPS & $92 \%$ & $72 \%$ \\
Raynaud's hasculitis & $96 \%$ & $88 \%$ \\
\hline
\end{tabular}

Hospital stay was short in those patients who underwent thoracoscopic sympathectomy, with most patients staying 1 or 2 days (Table 7). There was no cohort of patients who underwent open procedures to compare with the hospital stays of our patients; however, historical cohorts of patients who underwent posterior paraspinal sympathectomies have had hospital stays that ranged from 3 to 6 days. The overall complication rates (Table 8) were comparable to previous treatment alternatives. The one mortality occurred in an elderly patient with known cardiovascular risk factors who suffered a myocardial infarction 1 month after surgery; however, this patient had responded well to a sympathectomy for severe and refractory vasculitic symptoms.

\begin{tabular}{|lcc|}
\hline \multicolumn{3}{|c|}{$\begin{array}{c}\text { TABLE 7 } \\
\text { LENGTH OF HOSPTAL STAV FOLLOWING THORACOSCOPIC } \\
\text { SVMPATHEC TOMN }\end{array}$} \\
\hline \hline Duration & $\begin{array}{c}\text { Unilat SYmpat it } \\
\text { ectomy (day) }\end{array}$ & $\begin{array}{c}\text { Bilat Sympath- } \\
\text { ectomy (days) }\end{array}$ \\
\hline median & 1 & 2 \\
mean & 1.5 & 2.2 \\
range & $0-4$ & $0-3$ \\
\hline
\end{tabular}

\begin{tabular}{|c|c|}
\hline \multicolumn{2}{|c|}{$\begin{array}{c}\text { TABLE } 8 \\
\text { POSTOPERATIYE COMPLICATONS AFTER SYMPATHECTOM }{ }^{\star}\end{array}$} \\
\hline Postop Complications & No. of Patierts \\
\hline \multicolumn{2}{|l|}{ Horner's syndrome } \\
\hline transient & 6 \\
\hline permanent & 1 \\
\hline pneum othorax ( $w /$ chest tu be) & 1 \\
\hline pleural e fusion (wbut aspiration or chest tube) & 4 \\
\hline mound infection & 1 \\
\hline \multicolumn{2}{|l|}{ in tercostal neuralgia } \\
\hline transient & 3 \\
\hline permanent & 1 \\
\hline death & 1 \\
\hline
\end{tabular}

\section{DISCUSSION}

\section{Evolution of Sympathectomy Techniques}

Similar to other minimally invasive procedures that have attained reduced morbidity rates, techniques for thoracic sympathectomy have recently evolved to achieve improved patient care and outcomes.[4,8,17,19] Treatment of hyperhidrosis and sympathetically mediated pain disorders previously required highly invasive surgical procedures to resect a relatively small portion of the upper thoracic sympathetic ganglia. $[3,5,7,11,28,30,31]$ Despite the complex nature of these disorders and previous 
surgical procedures, they produced acceptable long-term clinical results.[3,5,7,11,26,31] Open operative procedures for hyperhidrosis have been established with resolution of symptoms in more than $95 \%$ of patients, and patients with pain disorders have had long-term improvement that ranged from 60 to $80 \% .[7,22,28,31]$ Open surgical procedures with thoracotomy, supraclavicular, or posterior paraspinal exposures, however, had significant morbidity rates due to large incisions, tissue retraction, and lengthy hospital stays with many weeks spent rehabilitating before returning to normal daily activity. Consequently, less traumatic and invasive procedures for sympathectomy have been sought.

\section{Percutaneous Procedures}

Percutaneous techniques have evolved from the use of diagnostic stellate blocks that are often useful in providing temporary symptomatic relief in the nonsurgical management of sympathetically mediated pain but also have predictive value in patients considered for a sympathectomy.[22,33] The first attempts at percutaneous procedures with alcohol injections to destroy the sympathetic ganglia in 1927 had varying and unreliable results.[32] In the past decade, other percutaneous techniques with phenol injections and radiofrequency lesioning of the sympathetic ganglia initially received interest but have not gained widespread acceptance due to local toxicity and high recurrence rates.[2,6,32,33]

\section{History of Thoracoscopic Procedures}

Thoracic endoscopic procedures were first performed by Jacobaeus[16] in 1910 for diagnosis of intrathoracic infectious and neoplastic diseases. The first thoracic endoscopic procedure for a sympathetic ganglionectomy was performed in 1942 by Hughes.[14] Kux[17] published his initial paper on endoscopic procedures involving the "vegetative nervous system" in 1951, then published his large series[18] of over 1400 endoscopic sympathectomies and vagotomies in 1954. In these early series, the indications for sympathectomy were diverse, including angina, hypertension, and gastric ulcers as well as hyperhidrosis and vasculitic/pain disorders.[17-19] Medical management has reduced the number of current indications for sympathectomy to hyperhidrosis and pain disorders, and most reports in the past decade reflect the resurgence of interest in thoracoscopic treatment of these disorders.[1,4,15,23,29] Similarly, public interest in minimally invasive surgery has increased due to shortened hospital stays, which has brought to light the relatively high incidence of these benign disorders.

\section{Hyperhidrosis}

Palmar hyperhidrosis is characterized primarily by excessive sweating in the hands and is aggravated by stress as minor as handshaking. The cause is unknown, and the incidence ranges from 0.15 to $1 \%$ but may be higher in Asian populations.[7,22,26,33] Excessive sweating of the hands has significant social and psychological impact on younger patients and may also have important economic and occupational implications for older patients. Because these severe symptoms are poorly controlled with medical or topical therapy, patients with these symptoms are good candidates for sympathectomy. Normal sweating results from sympathetic innervation of eccrine glands via cholinergic nerve fibers arising from the intermediolateral column of the thoracolumbar spinal cord. Cutaneous vasoconstriction results in further cooling when combined with excessive sweating.[25] Stellate ganglion blocks are useful but not essential in preoperative evaluation, resulting in a dramatic decrease in sweating and warming of the ipsilateral hand due to decreased sweat gland activity and increased blood flow through cutaneous arteriovenous fistulae.[1] Controversy exists regarding the necessary extent of sympathetic ganglion resection for treatment of hyperhidrosis.[11,13,22] Resection of the T-2 sympathetic ganglion results in sympathetic denervation of the lower trunk of the brachial plexus and dramatic relief of palmar hyperhidrosis 
symptoms in most patients. Some authors, however, have advocated more extensive denervation that includes the T3-4 ganglia and possibly the inferior aspect of the stellate for severe cases of axillary and palmar hyperhidrosis.[4,11,13,23,29] The primary difference in patients undergoing thoracoscopic sympathectomy is the smaller surgical exposures that allow rapid recovery and return to full activity following a brief hospital stay; this alone suggests cost effectiveness.

Hyperhidrosis is the primary indication for thoracic sympathectomy. In a recent study[26] involving 100 patients with hyperhidrosis the success rate was reported to be $98 \%$, which is consistent with our series. Investigators in a small prospective trial[12] of open supraclavicular compared with thoracoscopic sympathectomy for hyperhidrosis achieved equivalent results but concluded that open surgery may be preferable because of chest wall discomfort in the patients undergoing thoracoscopy; however, the trial lacked convincing statistical support with objective data. Analysis of results from our current outcome study suggest that patients had high overall satisfaction and they would undergo same treatment and procedures again.

The delayed complication rate of compensatory hyperhidrosis varies among the reported series, ranging from 12 to $45 \%$.[12,20,29] Thoracoscopic techniques may not change this, but only further studies will determined this. A remarkably small number of patients are dissatisfied with the compensatory symptoms in comparison to their previous symptoms of palmar sweating.

\section{Pain Syndromes}

Dysesthetic pain syndromes likely arise from peripheral nerve or extremity injuries, causing poorly understood syndromes of causalgia, reflex sympathetic dystrophy, and complex regional pain syndrome. Other sympathetically mediated pain syndromes include phantom pain, shoulder-hand syndrome, and postherpetic neuralgia.[14,22] Characteristic symptoms are typically a constant burning pain exacerbated by tactile stimulation and trophic skin changes. Medical therapy with narcotic, neuroleptic, or anticonvulsant drugs has limited long-term efficacy but can be used to augment an aggressive rehabilitation effort, which is the first line of treatment. Stellate ganglion blocks can be used to provide temporary relief lasting for days or weeks while a rehabilitation effort is ongoing. Patients with good responses to stellate blocks but who do not respond to rehabilitation efforts may be candidates for surgical treatment.[1] Ablative surgical procedures such as rhizotomy and cordotomy are complex and technically demanding and often produce limited efficacy, high recurrence rates, and involve significant potential for complications. Sympathectomy for selected patients offers remarkable symptomatic improvement; however, some patients (10-25\%) may have recurrences that vary in severity.[1,13,22] Patient selection likely plays an important role in the surgical outcome; ideal candidates have only dystrophic symptoms that have not progressed to chronic atrophic changes.[1,13]

Although the causes of recurrent pain symptoms are unclear, they may be related to incomplete denervation, and the regrowth of the sympathetic ganglion or receptor hypersensitivity have been postulated as causes.[1,20] Our current study does not indicate improved outcomes beyond previous reports, but further study is needed to determine if the extent of sympathetic chain resection plays a role in outcomes.

\section{Vasculitis/Raynaud's Syndrome}

Raynaud's syndrome is the most common vasculitic disorder causing ischemic pain in the hands and fingertips. Raynaud's syndrome is usually associated with collagen vascular diseases, and extreme cases 
result in ulceration of the digits.[10] These symptoms are typically exacerbated by cold temperatures or emotional responses, and the primary treatment is avoidance of cold. Medical therapy with calcium channel blockers and alpha-adrenergic blocking agents are recommended and often effective in most cases.[21] Patients with severe symptoms may respond to stellate blocks, and they may have good relief of symptoms from sympathectomy; however, results are controversial because of the variable recurrence of symptoms.[10,21] Despite our success and low recurrence rates, the small number of patients we treated does not allow us to make further conclusions. The reason for a significant failure rate is that vasculitic syndromes are considered systemic disorders that may not respond to local or regional surgical treatment, and some authors are firmly opposed to sympathectomy for treatment of Raynaud's syndrome.[10,21] Regardless, our results indicate that some proportion of patients with Raynaud's syndrome may respond to sympathectomy, and the criteria for patient selection remain difficult and unclear at this time.

\section{Complications From Thoracoscopy}

Most complications resulting from thoracoscopic sympathectomy are minor and self limited. Horner's syndrome generally occurred early in this series, and there were fewer occurrences in the patients treated later in this series, which may reflect the learning curve for surgical techniques. Horner's syndrome $[4,12,28]$ results from injury to the stellate ganglion and is fortunately infrequent and usually transient. Improved visualization with thoracoscopy would theoretically reduce the incidence of Horner's syndrome by providing identification of the stellate ganglion and allowing the surgeon to avoid the fibers ascending rostrally from the stellate, which innervate the ocular pupillary muscles, dividing the rami caudal to the stellate, and providing sympathetic innervation to the upper extremity.[28]

Intercostal neuralgia results from injury to the intercostal nerves that can occur during port placement or from direct pressure on the intercostal nerves during the procedure. Intercostal neuralgia also occurred more often in the patients treated earlier in our series and less frequently in the patients treated later, which may be due to several factors. Soft flexible ports are now used exclusively, and our current use of a 5-mm endoscope may further reduce the incidence of intercostal neuralgia. Hashmonai, et al.,[12] cited a lower incidence of intercostal neuralgia as the major difference comparing open supraclavicular with endoscopic sympathectomy; however these differences may only reflect the use of flexible ports or smaller instruments.

Small pleural effusions do not require drainage but should be followed with repeated chest radiography.[4,12,20] Pnuemothorax indicates a parenchymal or port-site leak. A small pneumothorax can be observed, but a large pneumothorax requires chest tube replacement.

The one death in this series occurred several weeks after surgery in a patient with known risk factors who was otherwise doing well after surgery. Cardiac function and catecholamines are not significantly changed following sympathectomy, and they are unlikely to have clinically significant cardiac and hemodynamic alterations.[24-27]

\section{CONCLUSIONS}

Minimally invasive techniques for thoracoscopic sympathectomy have equivalent outcomes as previous open surgical techniques for sympathetically mediated disorders; however, the associated morbidity rate and hospital stay are substantially reduced with these newer techniques. Formal training for these procedures is recommended with didactic and laboratory training followed by work with an experienced 
surgeon who performs these procedures on a regular basis.

\section{Acknowledgments}

The authors would like to thank Joe Bloch for his artistic illustrations and Samantha Phu for assistance with this manuscript.

\section{References}

1. AbuRahma AF, Robinson PA, Powell M, et al: Sympathectomy for reflex sympathetic dystrophy: factors affecting outcome. Ann Vasc Surg 8:372-379, 1994

2. Adler OB, Engel A, Rosenberger A, et al: Palmar hyperhydrosis CT guided chemical percutaneous thoracic sympathectomy. Fortschr Rontgenstr 153:400-403, 1990

3. Adson AW: Changes in technique of cervico-thoracic ganglionectomy and trunk resection. Am J Surg 23:287-288, 1934

4. Ahn SS, Machleder HI, Concepcion B, et al: Thoracoscopic cervicodorsal sympathectomy: preliminary results. J Vasc Surg 20:511-519, 1994

5. Atkins HBJ: Sympathectomy by the axillary approach. Lancet 1:538-539, 1954

6. Chuang KS, Liou NH, Liu JC: New stereotactic technique for percutaneous thermocoagulation of upper thoracic ganglionectomy in cases of palmar hyperhidrosis. Neurosurgery 22:600-604, 1988

7. Cloward RB: Hyperhidrosis. J Neurosurg 30:545-551, 1969

8. Drott C: The history of cervicothoracic sympathectomy. Eur J Surg (Suppl) 572:5-7, 1994

9. Dumont P, Hamm A, Skrobala D, et al: Bilateral thoracoscopy for sympathectomy in the treatment of hyperhidrosis. Eur J Cardothorac Surg 11:774-775, 1997

10. Edwards JM, Porter JM: Associated diseases with Raynaud's syndrome. Vasc Med Rev 1:51-58, 1990

11. Goetz RH, Marr JAS; The importance of the second thoracic ganglion for the sympathetic supply of the upper extremities, with a description of two new approaches for its removal in cases of vascular disease: preliminary report. Clin Proc 3:102-114, 1944

12. Hashmonai M, Kopelman D, Schein M: Thoracoscopic versus open supraclavicular upper dorsal sympathectomy: a prospective randomised trial. Eur J Surg (Suppl) 572:13-16, 1994

13. Herz DA, Looman JE, Ford RD, et al: Second thoracic sympathetic ganglionectomy in sympathetically maintained pain. J Pain Symptom Manage 8:483-491, 1993

14. Hughes J: Endothoracic sympathectomy. Proc R Soc Med 35:585-586, 1942

15. Jacobaeus HC: Über die Möglichkeit die zystoskopie bei Untersuchung seröser Höhlungen anzuwenden. Munch Med Wochenschr 40:2090-2092, 1910

16. Kao MC, Tsai JC, Lai DM, et al: Autonomic activities in hyperhidrosis patients before, during, and 
after endoscopic laser sympathectomy. Neurosurgery 34:262-268, 1994

17. Kux E: The endoscopic approach to the vegetative nervous system and its therapeutic possibilities. Dis Chest 20:139-147, 1951

18. Kux E: Thorakoskopische Eingriffe am Nervensystem. Stuttegart: Thieme, 1954

19. Kux M: Thoracic endoscopic sympathectomy in palmar and axillary hyperhidrosis. Arch Surg 113:264-266, 1978

20. Lai YT, Yang LH, Chio CC, et al: Complications in patients with palmar hyperhidrosis treated with transthoracic endoscopic sympathectomy. Neurosurgery 41:110-113, 1997

21. Landry GJ, Edwards JM, Porter JM: Current management of Raynaud's syndrome. Adv Surg 30:333-347, 1996

22. Mockus MB, Rutherford RF, Rosales C, et al: Sympathectomy for causalgia. Patient selection and long-term results. Arch Surg 122:668-672, 1987

23. Nicholson ML, Dennis MJS, Hopkinson BR: Endoscopic transthoracic sympathectomy: successful in hyperhidrosis but can the indications be extended? Ann R Coll Surg Engl 76:311-314, 1994

24. Noppen M, Dendale P, Hagers Y, et al: Changes in cardiocirculatory autonomic function after thoracoscopic upper dorsal sympathicolysis for essential hyperhidrosis. J Autonom Nerv Syst 60:115-120, 1996

25. Noppen M, Herregodts P, Dendale P, et al: Cardiopulmonary exercise testing following bilateral thoracoscopic sympathicolysis in patients with essential hyperhidrosis. Thorax 50:1097-1100, 1995

26. Noppen M, Herregodts P, D'Haese J, et al: A simplified T2-T3 thoracoscopic sympathicolysis technique for the treatment of essential hyperhidrosis: short-term results in 100 patients. J Laparoendosc Surg 6:151-159, 1996

27. Noppen M, Sevens C, Gerlo E , et al: Plasma catecholamine concentrations in essential hyperhidrosis and effects of thoracoscopic D2-D3 sympathicolysis. Eur J Clin Invest 27:202-205, 1997

28. Roos DB: Transaxillary extrapleural thoracic sympathectomy, in Bergan JJ, Yao JST (eds):

Operative Techniques in Vascular Surgery. New York: Grune \& Stratton, 1980, p 115

29. Samuelsson H, Claes G, Drott C: Endoscopic electrocautery of the upper thoracic sympathetic chain: a safe and simple technique for treatment of sympathetically maintained pain. Eur J Surg (Suppl) 572:55-57, 1994

30. Telford ED: The technique of sympathectomy. Br J Surg 23:448-450, 1935

31. White JC, Smithwick RH, Allen AW, et al: A new muscle splitting incision for resection of the upper thoracic sympathetic ganglia. Surg Gynecol Obstet 56:651-657, 1933

32. White JC, White PD: Angina pectoris: treatment with paravertebral alcohol injections. JAMA 90:1099-1103, 1928

33. Wilkinson HA: Percutaneous radiofrequency upper thoracic sympathectomy: a new technique. 
Manuscript received January 22, 1998.

Accepted in final form January 25, 1998.

Address reprint requests to: J. Patrick Johnson, M.D., Division of Neurosurgery, University of California, Los Angeles, Box 956901, Los Angeles, California 90095-6901. email:

johnson@surgery.medsch.ucla.edu 